\title{
A Novel Identification Scheme of Lightning Disturbance in HVDC Transmission Lines Based on CEEMD-HHT
}

\author{
Dongmeng YE, Fan XIE, and Zhiguo HAO
}

\begin{abstract}
For high-voltage direct current (HVDC) transmission systems that use overhead transmission lines, the lightning disturbance is the main reason for the line protection mal-operation. To avoid the impact of lightning disturbance on the safety and stability of DC line protection, the model of HVDC transmission system including lightning strokes is constructed. On this basis, the complementary ensemble empirical mode decomposition (CEEMD) and Hilbert transform are combined as a time-frequency analysis method to calculate the energy distribution of the signals. Then the low-to-high-frequency energy ratio of the 1-mode voltage signal in a $3 \mathrm{~ms}$ data window after the protection startup is used as the protection criterion for identifying lightning disturbance, and that of the current signal in $\mathbf{1} \mathrm{ms}$ is used as the criterion to further distinguish lightning and non-lightning faults. Verified through simulation tests, the scheme appears good adaptability and accuracy in different situations.
\end{abstract}

Index Terms - CEEMD-HHT, disturbance identification, HVDC line protection, lightning stroke.

\section{INTRODUCTION}

A $\mathrm{S}$ a result of the fossil energy shortage, it is imperative to transit the use and development of energy to renewable clean energy. Compared with AC transmission, HVDC transmission has the advantages of low cost, single structure, large transmission capacity and unrestricted transmission distance, which has made it a vital technology to enable long-distance power transmission and to construct a future grid based on renewables [1]-[3].

Since the HVDC transmission line is the component with the highest fault probability in the transmission system, improving its relay protection performance is the key to ensuring the safety of power system. Compared with cable transmission, the use of overhead lines is more economical. However, the main protection principle of overhead lines based on transients is vulnerable to the high-frequency signal injected by lightning strokes [4]. Hence, it is necessary to accurately distinguish lightning disturbance from lightning faults and non-lightning

Manuscript received February 27, 2021; revised May 13, 2021; accepted May 21, 2021. Date of publication June 30, 2021; date of current version June 18, 2021. This paper was presented in part at the 4th International Conference on HVDC (HVDC 2020), Xi'an, China, September 2020.

All authors are with School of Electrical Engineering, Xi'an Jiaotong University, Xi'an, Shannxi, 710000, China.

Digital Object Identifier 10.24295/CPSSTPEA.2021.00013 faults. Meanwhile, usually the fault developing process and the protective measures vary with faults caused by different reasons. Therefore, a further distinction should be made between lightning faults caused by lightning strikes, and nonlightning faults, such as ordinary short-circuit faults. This can provide important data support for the protection, operation and maintenance of HVDC lines.

Scholars over the world have already carried out a large number of studies on lightning disturbance identification schemes. Research results are concentrated in the following aspects: 1) time-domain-based schemes, 2) frequency-domainbased schemes and 3) the artificial-intelligence (AI)-based schemes.

In the time domain, mathematical methods are used to extract numerical characteristics such as integral value [5], mutation rate [6], mean value [7], and variance [8] of non-unit signals to form protection criteria. Reference [9] utilizes the difference of the polarities of the voltage 0 -mode component to determine whether a shielding failure or a backflash has occurred. These methods above utilize the timedomain numerical features and the calculation is simple, but the threshold is vulnerable to lightning parameters. In addition, it is also feasible to extract time-domain waveform features using signal processing methods such as correlation analysis [10], [11], morphological multi-scale analysis [12] and MMG transformation [13]. This type of method usually has a clear setting principle, but the extraction of the waveform features based on a long data window is difficult to cooperate with ultra-high-speed transient protection [14].

In the frequency domain, from the perspective of energy distribution in the frequency spectrum, wavelet transform (WT) [15], [16] and other time-frequency transformation methods can also distinguish lightning disturbances and faults. As a time-frequency analysis method, WT can effectively divide the frequency band of the signal and appears good time locality, but the selection of the wavelet base and the determination of parameters rely strongly on experience. Reference [17] uses empirical mode decomposition (EMD) to decompose the voltage signal into multiple intrinsic mode functions (IMFs) and calculates the integrated value of the lowest frequency IMF as a protection criterion. Besides, the S-transform [18], Chebyshev filter [19], etc. can also effectively extract the difference between faults and disturbance. However, the above methods require relatively complicated algorithms and large calculation. 
Also, as the high-frequency component is rapidly attenuated when a high-impedance fault occurs, these methods sometimes appear low reliability and feasibility in actual applications [20].

Furthermore, in recent years, the application of artificial intelligence (AI), including convolutional neural network with branch structures (BR-CNN) [21], stack auto-encoder (SAE) [22], support vector machine (SVM) [23] and other methods, has become increasingly widespread to identify lightning disturbance. Through offline learning of previous experience, lightning disturbance and fault waveform features can be implicitly extracted, thereby realizing the classification without complicated mathematical techniques [24]. However, only a few training samples for faults in reality, hence a large number of training samples need to be obtained by simulation and the classifier may have poor adaptability to the actual power system.

To overcome the difficulty of threshold setting and the defect of long data windows of time-domain-based methods, as well as the excessive dependence on simulation examples of AI methods, an identification scheme is proposed from the perspective of frequency domain energy distribution. As is verified through simulation tests, the judgment made by this scheme can achieve high accuracy. Also, it requires lower calculation speed and storage capacity, and is almost unaffected by lightning current parameters and transition resistance.

In the remaining parts of this paper, first the HVDC transmission model including lightning strokes is constructed on PSCAD/ EMTDC in Section II. In Section III, the time and frequency domain features of lightning disturbance, lightning fault and non-lightning fault are analyzed. To extract these features, as EMD may have unavoidable mode aliasing phenomenon for noisy signals, which affects the accuracy of decomposition, it is replaced with complementary ensemble empirical mode decomposition (CEEMD), combined with Hilbert-Huang Transform (HHT) to calculate the low-to-high-frequency energy ratios in Section IV. On this basis, a lightning disturbance identification scheme is proposed to distinguish the above three cases. The efficiency of the scheme has been verified in Section V.

\section{HVDC TRANSMISSION SYSTEM INCLUDING LIGHTNING STROKES}

\section{A. HVDC Transmission System and Control System Model}

This model [25], [26] uses parameters of a bipolar 12-pulse $\pm 500 \mathrm{kV}$ DC transmission project based on PSCAD/EMTDC, as is shown in Fig. 1. The sending-end converter station is usually used as a rectifier station and the receiving-end converter station as an inverter station. The total length of the line is 1043 kilometers.

The DC transmission primary system includes DC transmission lines, converter transformers, converter valves, AC filter banks and reactive power compensation, DC filter banks and smoothing reactors.

\section{B. Lightning Stroke Model}

\section{1) Lightning Discharging Model}

Bruce and Godle proposed a double exponential function of

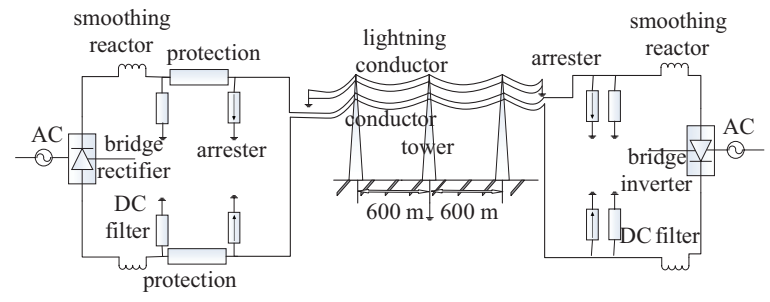

Fig. 1. HVDC transmission system and control system model.

TABLE I

Lightning Current Parameters

\begin{tabular}{lccc}
\hline \hline $\begin{array}{l}\text { Lightning } \\
\text { waveform }\end{array}$ & $\begin{array}{c}\text { Waveform } \\
\text { correction } \\
\text { coefficient } k\end{array}$ & $\begin{array}{c}\text { Wave tail } \\
\text { attenuation } \\
\text { coefficient } \alpha\end{array}$ & $\begin{array}{c}\text { Wave head } \\
\text { attenuation } \\
\text { coefficient } \beta\end{array}$ \\
\hline $1.2 / 50 \mu \mathrm{s}$ & 1.021 & 14400 & 4814400 \\
$2.6 / 50 \mu \mathrm{s}$ & 1.043 & 14730 & 2080000 \\
$5 / 100 \mu \mathrm{s}$ & 1.046 & 7429 & 1004400 \\
\hline \hline
\end{tabular}

lightning current waveform [27], [28] based on the measured exponentially rising and falling law of lightning current in 1941, as in:

$$
i_{0}(t)=k I_{0}\left(e^{-\alpha t}-e^{-\beta t}\right)
$$

Where $i_{0}(t)$ is the instantaneous amplitude of lightning current, with $\mathrm{kA}$ as the unit, $k$ is the waveform correction coefficient, $I_{0}$ is the peak value of the lightning current, with $\mathrm{kA}$ as the unit, and $\mathrm{a}, \mathrm{b}$ are the attenuation coefficients of the wave tail and wave head of the lightning current, respectively.

The wave head of lightning waveform usually ranges within 1-5 $\mu \mathrm{s}$, mostly $2.5-2.6 \mu \mathrm{s}$, and the half-peak time usually ranges within 20-100 $\mu$ s, mostly about $50 \mu \mathrm{s}$ [29]. In order to obtain more comprehensive simulation results, this paper selects three types of lightning current waveforms: $1.2 / 50 \mu \mathrm{s}$, $2.6 / 50 \mu \mathrm{s}$ and $5 / 100 \mu \mathrm{s}$, the specific parameters are shown in Table I.

\section{2) Insulator String Flashover Model}

The equivalent model of the insulator string can be represented by a parallel connection of the coupling capacitance between the wires and the voltage-controlled switch [30]. This paper uses the $50 \%$ breakdown voltage method and the volt-second characteristic method to determine whether the insulator string is flashover. When the voltage across the capacitor is greater than one of the preset thresholds, the voltage-controlled switch is closed.

\section{3) Arrester Model}

When the overvoltage generated by operation or lightning stroke exceeds a certain value, the surge arrester will first be broken down and discharged to the ground, thereby preventing the overvoltage from breaking down the electrical equipment. As a highly nonlinear resistance, the mathematical model of the arrester can be expressed by its volt-ampere characteristics [31]. 


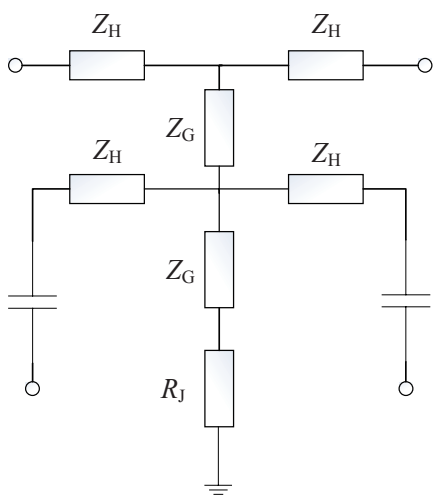

Fig. 2. Multi-wave impedance model of tower.

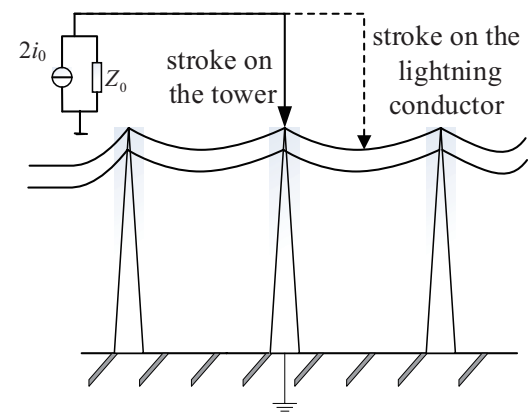

(a) Shielding failure

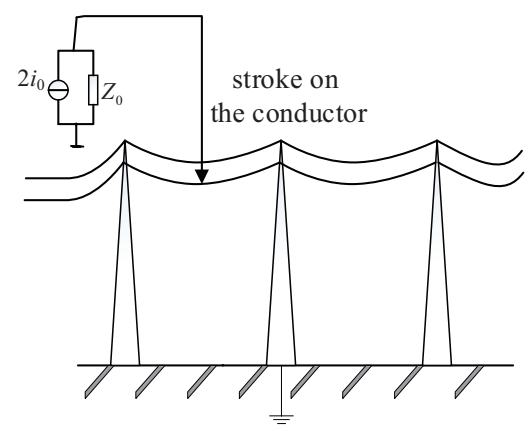

(b) Back-flash

Fig. 3. 2 types of lightning strokes.

\section{4) Tower Model}

For the $\pm 500 \mathrm{kV}$ line with a high pole tower, the multi-surgeimpedance model [32] of the pole tower is used in this paper.

As shown in Fig. 2, the model considers the wave process on the pole tower, and that the parameter varies with the height of the tower, which makes it the most accurate calculation model. Among them, $Z_{\mathrm{H}}$ is the surge impedance of the transverse $(200 \Omega), Z_{\mathrm{G}}$ is the surge impedance of the tower $(150 \Omega)$, and $R_{\mathrm{J}}$ is the grounding resistance.

To combine the lightning stroke model with the original HVDC transmission system, lightning strokes are divided by their locations into shielding failure and back-flash. Shielding failure refers to the lightning stroke induced to the line, or lightning striking on the tower or the lightning conductor, and back-flash means lightning striking on the conductor. The specific locations to add them to the transmission line is shown in Fig. 3.

\section{Transient Characteristic Analysis}

This chapter will analyze the time-frequency transient characteristics from the perspective of time-domain waveforms and frequency-domain energy distribution for cases that occur at $1 \mathrm{~ms}$ on the time axis on the DC transmission line $450 \mathrm{~km}$ away from the rectifier station.

\section{A. Phase-Mode Transformation}

In order to eliminate the influence of electromagnetic coupling between the two poles, firstly, use the following phase-mode transformation matrix [33] to decouple phasors:

$$
\left\{\begin{array}{l}
S=\frac{1}{\sqrt{2}}\left[\begin{array}{ll}
1 & 1 \\
-1 & 1
\end{array}\right] \\
S^{-1}=S^{T}
\end{array}\right.
$$

It can be deduced:

$$
\left\{\begin{array}{l}
{\left[\begin{array}{l}
u_{1} \\
u_{0}
\end{array}\right]=S^{-1}\left[\begin{array}{l}
u_{\mathrm{p}} \\
u_{\mathrm{n}}
\end{array}\right]} \\
{\left[\begin{array}{l}
i_{1} \\
i_{0}
\end{array}\right]=S^{-1}\left[\begin{array}{l}
i_{\mathrm{p}} \\
i_{\mathrm{n}}
\end{array}\right]}
\end{array}\right.
$$

where $u_{\mathrm{p}}, u_{\mathrm{n}}, i_{\mathrm{p}}, i_{\mathrm{n}}$ are the positive and negative voltages and currents at the protection, respectively, and $u_{1}, u_{0}, i_{1}$ and $i_{0}$ are the 1 -mode and 0 -mode voltages and currents, respectively.

\section{B. Analysis of Transient Characteristics of Lightning Disturbance}

For the convenience of analysis, $\rho_{\mathrm{U}}$ and $\rho_{\mathrm{I}}$ are defined as the low-to-high-frequency energy ratios of the 1-mode voltage and current, respectively:

$$
\left\{\begin{array}{l}
\rho_{\mathrm{U}}=\frac{E_{\mathrm{LF}_{-} \mathrm{U}}}{E_{\mathrm{HF}_{-} \mathrm{U}}} \\
\rho_{\mathrm{I}}=\frac{E_{\mathrm{LF}_{-} \mathrm{I}}}{E_{\mathrm{HF}_{-} \mathrm{I}}}
\end{array}\right.
$$

where $E_{\mathrm{HF}_{\mathrm{U}}}, E_{\mathrm{LF}_{\mathrm{U}}}, E_{\mathrm{HF}_{\mathrm{I}}}$ and $E_{\mathrm{LF}_{-} \mathrm{I}}$ are the energy of the highfrequency (frequency higher than $1 \mathrm{kHz}$ ) and low-frequency components of the 1-mode voltage and current, respectively, defined as:

$$
\left\{\begin{array}{l}
E_{\mathrm{LF}_{-} \mathrm{U}}=\int_{0}^{1 \mathrm{kHz}} U_{1}^{2}(f) \mathrm{d} f \\
E_{\mathrm{HF} \_\mathrm{U}}=\int_{1 \mathrm{kHz}}^{f_{s}} U_{1}^{2}(f) \mathrm{d} f \\
E_{\mathrm{LF}_{-} \mathrm{I}}=\int_{0}^{1 \mathrm{kHz}} I_{1}^{2}(f) \mathrm{d} f \\
E_{\mathrm{HW}_{-} \mathrm{I}}=\int_{1 \mathrm{kHz}}^{f_{s}} I_{1}^{2}(f) \mathrm{d} f
\end{array}\right.
$$




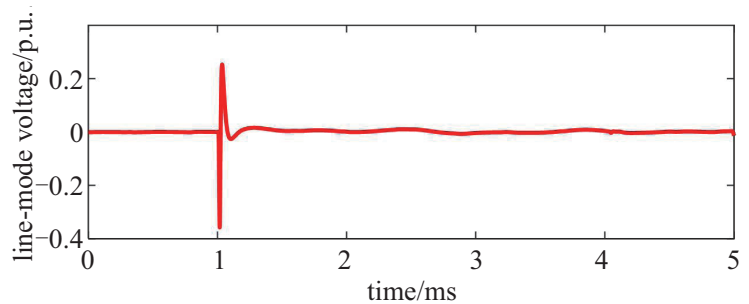

(a) Shielding failure without flashover

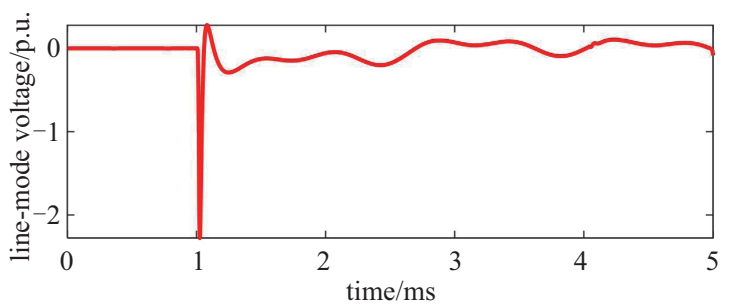

(b) Back-flash without flashover

Fig. 4. 1-mode voltage fault component when lightning disturbance occurs.

Sorted by their locations, lightning disturbance can also be divided into shielding failure and back-flash without flashover.

Fig. 4 shows the 1-mode voltage fault component waveforms in the above two situations. When the lightning disturbance occurs, traveling wave transmitted to both ends of the line contains high-frequency components and causes instantaneous overvoltage. But since no insulation flashover occurs, no fault current enters the ground at the striking point. Therefore, the fault component fluctuates around the 0 axis. Also, due to the damping of the system [34], the fault component gradually decays over time.

For shielding failure without flashover, as the coupling coefficient is close, the induced voltages on the two poles have the same polarity, similar amplitudes and waveforms, the 1-mode voltage is almost unchanged, as can be seen from Fig. 4(a), leading to very low $E_{\mathrm{LF}_{-} \mathrm{U}}$ and therefore a small $\rho_{\mathrm{U}}$.

However, for back-flash without flashover, as voltages on the poles are of opposite polarities, causing a large change in 1-mode voltage. As can be seen from Fig. 4(b), the amplitude of the voltage change with high frequency and relatively large amplitude, leading to high $E_{\mathrm{HF}_{-} \mathrm{U}}$ and therefore a small $\rho_{\mathrm{U}}$.

\section{Analysis of Transient Characteristics of Lightning Fault}

If the lightning current amplitude is increased continuously, insulator flashover will occur within a few microseconds after the lightning strike. Corresponding to lightning disturbance, lightning fault can also be divided into shielding failure with flashover and back-flash with flashover. Fig. 5 shows the 1-mode voltage and current fault component waveforms in the above two situations.

This process can be divided into three stages: firstly, immediately lightning current is injected into the line; then the transient voltage of the insulator is gradually established; finally, the voltage grows higher than the withstand voltage, and the

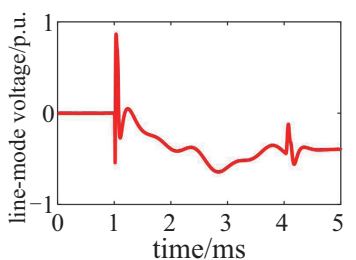

(a) Shielding failure with flashover voltage

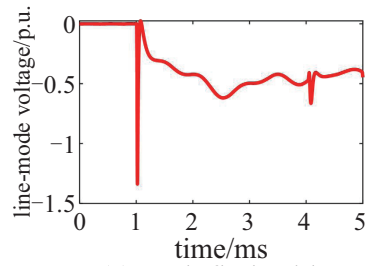

(c) Back-flash with flashover voltage

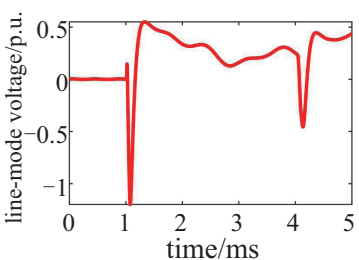

(b) Shielding failure with flashover current

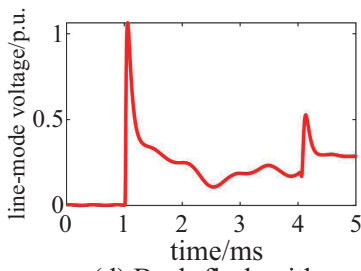

(d) Back-flash with flashover current
Fig. 5. 1-mode voltage and current fault component when a lightning fault occurs.

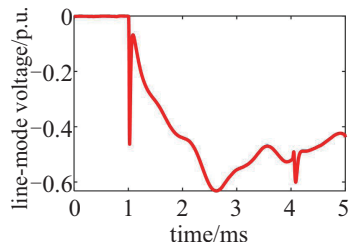

(a) Pole-to-ground fault voltage

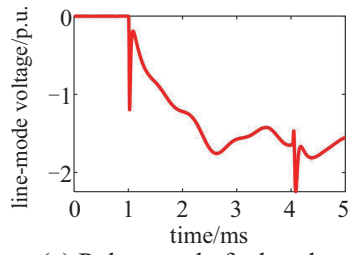

(c) Pole-to-pole fault voltage

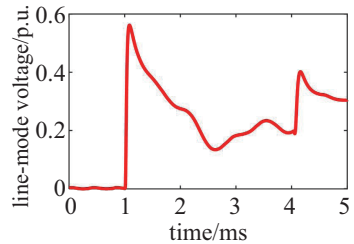

(b) Pole-to-ground fault current

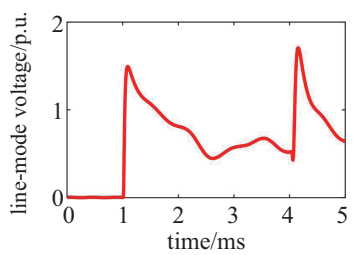

(d) Pole-to-pole fault current
Fig. 6. 1-mode voltage and current fault component when a non-lightning fault occurs.

flashover occurs. It can be seen that the first stage is equivalent to the occurrence of lightning disturbance, and the latter two stages presents the characteristics of an ordinary pole-toground short-circuit. It can be seen from Fig. 5(a) and (c) that after the flashover, as the positive voltage gradually deviates while the negative voltage still fluctuates around 0 , the 1-mode voltage component of the two types of lightning faults shows a large low-frequency change, with high $E_{\mathrm{LF}_{-} \mathrm{U}}$, low $E_{\mathrm{HF}_{-} \mathrm{U}}$, and therefore, a relatively large $\rho_{\mathrm{U}}$.

From Fig. 5(b) and (d), it can be derived that shortly after the lightning stroke, the 1-mode component of the current change sharply. This results in a relatively low $E_{\mathrm{LF}_{-}}$, a high $E_{\mathrm{HF}_{-}}$, and therefore a small ratio $\rho_{\mathrm{I}}$ in a short period.

\section{Analysis of Transient Characteristics of Non-Lightning Fault}

Fig. 6 shows the 1-mode voltage and current fault component waveforms when a pole-to-ground or pole-to-pole short-circuit fault happens. 
When a pole-to-ground short-circuit fault occurs, the fault voltage at the fault pole drops suddenly, and the non-fault pole fluctuates around 0 . When a pole-to-pole short-circuit fault occurs, the changes in the two pole voltages are completely opposite. Thus, it can be seen from Fig. 6(a) and (c) that just like a lightning fault, 1-mode voltage component exhibits large low-frequency changes with high $E_{\mathrm{LF}_{-} \mathrm{U}}$, low $E_{\mathrm{HF}_{-} \mathrm{U}}$ and a relatively large $\rho_{\mathrm{U}}$.

However, as it is no longer affected by high-frequency lightning current, these high-frequency transient components have lower frequencies and smaller amplitudes. As can be seen from Fig. 6(b) and (d), within a short time (approximately 1 $\mathrm{ms}$ ) after the fault, the 1-mode current component changes more slowly and the amplitude is lower with high $E_{\mathrm{LF}}$, low $E_{\mathrm{HF}}$, and a large $\rho_{\mathrm{I}}$.

\section{ACEEMD-HHT-BASEd Lightning DisturBance IDENTIFICTION SCHEME}

According to the previous analysis, it is convenient to extract the differences in the energy distribution of different frequency bands for various anomalies and faults. This paper uses CEEMD instead of EMD, combined with HHT to obtain the instantaneous frequency spectrum of the signal, and the low-frequency and high-frequency energy distribution of the 1-mode component of voltage and current are calculated.

\section{A. Basic Theory of CEEMD-HHT Algorithm}

HHT consists of two parts: EMD and Hilbert transform. First, each IMF that constitutes a non-stationary signal is obtained using EMD. For a time series $x(t)$ with a total decomposition order of $n$, it can be finally decomposed using EMD into:

$$
x(t)=\sum_{i=1}^{n} c_{i}(t)+r_{n}(t)
$$

where $r_{\mathrm{n}}(t)$ is the monotone residual function; $c_{\mathrm{i}}(t)$ is the IMF that constitutes the non-stationary signal [35].

However, discontinuous or noisy signals will inevitably cause the mode aliasing phenomenon, seriously affecting the accuracy of signal decomposition. In order to overcome this problem, Huang proposed ensemble empirical mode decomposition (EEMD), an improved method for EMD in 2009. He introduces Gaussian white noise into the original signal for many times, and averages the calculated IMFs as a result of decomposition. However, this method has the problem of noise residuals, and increases the number of sets at the expense of increasing computational cost to reduce reconstruction errors, so it cannot be used as a complete decomposition method.

After continuous improvement of the method, Torres proposed CEEMD in 2011. the residual noise in the reconstructed signal is effectively suppressed, and a better modal spectrum separation result can be obtained. The original signal can be accurately reconstructed under the computational cost.

In CEEMD, positive and negative white noise is introduced into the original signal at the same time, and two IMF sets are obtained, as shown in (7).

$$
\left[\begin{array}{l}
M_{1} \\
M_{2}
\end{array}\right]=\left[\begin{array}{cc}
1 & 1 \\
1 & -1
\end{array}\right]\left[\begin{array}{l}
S \\
N
\end{array}\right]
$$

Among them, $S$ is the original signal, $N$ is the white noise, $M_{1}$ and $M_{2}$ are the signals after adding positive and negative paired white noises respectively.

Define operator $E_{\mathrm{j}}(\bullet)$ as the $j$-th mode component of the signal obtained by EMD, and $\omega_{\mathrm{i}}(t)$ represents Gaussian white noise $(i=1,2,3 \ldots n) . \varepsilon_{\mathrm{k}}$ represents the signal-to-noise ratio at the $k$-th stage of decomposition $(k=1,2,3 \ldots K)$, and $K$ is the total number of modes. The specific decomposition steps of CEEMD are as follows [36]:

1) $N$ types of Gaussian white noise are added to the original signal in a fixed ratio, and $N$ IMFs will be obtained after $N$ times of EMD. Calculate the average value to get the first $\operatorname{IMF} c_{1}(\mathrm{t}):$

$$
c_{1}(t)=\frac{1}{N} \sum_{i=1}^{N} E_{1}\left[x(t)+\varepsilon_{0} \omega_{i}(t)\right]
$$

2) For $k=1,2,3 \ldots K$, obtain the $k$-th residual, calculate as follows to obtain the $(k+1)$-th $\operatorname{IMF} c_{k+1}(t)$ :

$$
c_{k+1}(t)=\frac{1}{N} \sum_{i=1}^{N} E_{1}\left\{r_{k}(t)+\varepsilon_{k} E_{k}\left[\omega_{i}(t)\right]\right\}
$$

3) Repeat the steps above until there are no more than two the residual extreme points.

The Hilbert transform for signal $x(t)$ is defined as:

$$
\hat{x}(t)=\frac{1}{\pi} \int_{-\infty}^{+\infty} \frac{x(\tau)}{t-\tau} \mathrm{d} \tau=\frac{1}{\pi} \int_{-\infty}^{+\infty} \frac{x(t-\tau)}{\tau} \mathrm{d} \tau=x(t) * \frac{1}{\pi t}
$$

The Hilbert transform can be widely used to obtain narrowband signals and instantaneous frequencies. On the one hand, it connects the amplitude frequency and phase frequency of the Fourier transform of the real causal signal. On the other hand, it can construct an analytical signal to eliminate its negative frequency components and reduce signal sampling rate. The physical characteristics such as the instantaneous amplitude $a(t)$, the instantaneous phase $\Phi(t)$, the instantaneous frequency $f(t)$ and the Hilbert-Huang spectrum of each IMF are obtained through Hilbert transform [37] using the calculation formula below:

$$
\left\{\begin{array}{l}
a(t)=\sqrt{x(t)^{2}+\hat{x}(t)^{2}} \\
\Phi(t)=\arctan \frac{\hat{x}(t)}{x(t)} \\
f(t)=\frac{\omega(t)}{2 \pi}=\frac{1}{2 \pi} \frac{\mathrm{d} \Phi(t)}{\mathrm{d} t}
\end{array}\right.
$$

\section{B. Algorithm Flow}

The third chapter separately analyzes the transient charac- 


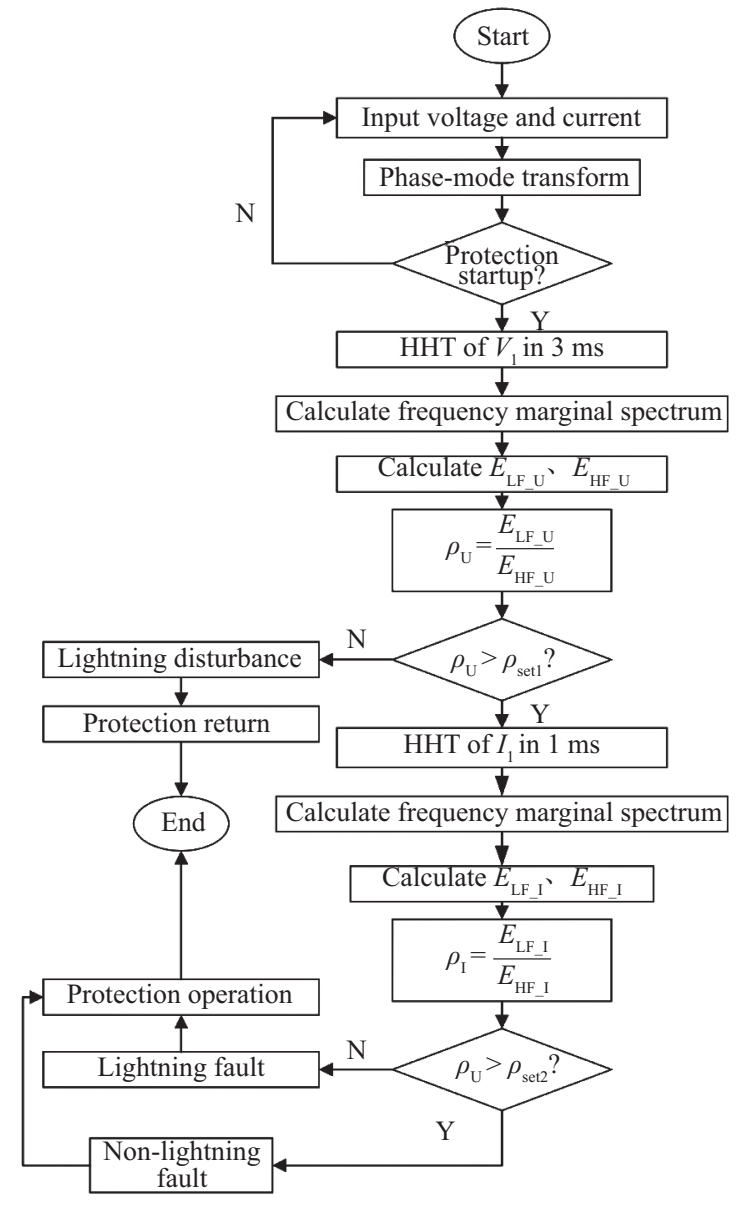

Fig. 7. Flow chart of the identification scheme.

teristics of lightning disturbance, lightning fault and nonlightning fault, which are summarized as follows:

- When the lightning stroke is not faulty, the ratio $\rho_{\mathrm{U}}$ is small; when a lightning fault or a non-lightning fault occurs, this value is larger.

- In the short time window (about $1 \mathrm{~ms}$ ) after the line is struck by lightning, the 1-mode current component has a smaller $\rho_{\mathrm{I}}$ than a non-lightning fault.

So far, based on the CEEMD-HHT algorithm, the ratio $\rho_{\mathrm{U}}$ within $3 \mathrm{~ms}$ is used as a criterion for identifying lightning disturbance, and the ratio $\rho_{\mathrm{I}}$ within $1 \mathrm{~ms}$ is used as a further distinction criterion for lightning faults and non-lightning fault. The algorithm flow is shown in Fig. 7:

Specific steps are as follows:

1) Collect positive and negative voltage and current on the rectifier side;

2) Perform phase-mode transform to obtain the 1-mode component of the voltage and current;

3) Set the protection start time as $t$, and record the 1-mode component in $[t, t+3]$ after startup;

4) Perform CEEMD-HHT on the 1-mode voltage component in $3 \mathrm{~ms}$;

5) Calculate as follows to obtain the marginal frequency spectrum:

$$
E(f)=\int_{t}^{t+3} U_{1}^{2}(f, \tau) \mathrm{d} \tau
$$

6) Calculate $E_{\mathrm{LF}_{-} \mathrm{U}}, E_{\mathrm{HF}_{-} \mathrm{U}}$ and $\rho_{\mathrm{U}}$, if $\rho_{\mathrm{U}}$ is smaller than the threshold $\rho_{\text {set }}$, it is judged as lightning disturbance, the protection returns and the algorithm ends, otherwise, go to step 7);

7) Perform CEEMD-HHT on the 1-mode current component in $1 \mathrm{~ms}$; Calculate as follows to obtain the marginal frequency spectrum:

$$
E(f)=\int_{t}^{t+3} I_{1}^{2}(f, \tau) \mathrm{d} \tau
$$

8) Calculate $E_{\mathrm{LF} \text { I }}, E_{\mathrm{HF}_{\mathrm{I}} \mathrm{I}}$ and $\rho_{\mathrm{I}}$, if $\rho_{\mathrm{I}}$ is smaller than the threshold $\rho_{\text {set2 } 2}$, it is judged as a lightning fault, otherwise, it is judged as a non-lightning fault. The protection operates and the algorithm ends.

\section{Threshold Determination}

An effective principle of threshold setting is the basic prerequisite for improving protection performance [38]. To realize the identification of lightning disturbance and further distinguish between lightning and non-lightning faults, it is necessary to determine the threshold value of the protection criterion. In order to satisfy the reliability and selectivity of the relay protection, both thresholds consider the most unfavorable conditions for the protection to operate during the setting, and a margin should be left [39].

Considering the effects of lightning current parameters, reflected traveling waves, etc., when identifying lightning disturbances, the fault with the weakest fault characteristic that occurs inside the line is shielding failure with flashover that occurs close to the protection, which appears the smallest $\rho_{\mathrm{U}}$. In this case, $\rho_{\mathrm{U}}=6.1439$, divided by a reliability factor 1.5 , the threshold to identify lightning disturbance $\rho_{\text {set }}=3.4133$.

When distinguishing lightning faults and non-lightning faults, consider that the non-lightning fault with the weakest fault characteristics is pole-to-ground short-circuit fault that occurs close to the protection, with $\rho_{\mathrm{I}}=15.9541$, divided by the reliability factor, thus the threshold to identify lightning and non-lightning fault $\rho_{\mathrm{se} 2}=10.6361$.

\section{Simulation Tests}

\section{A. Lightning Disturbance}

Table II examines the situations of different types of lightning disturbance caused by three different lightning current parameters at the same position of the line $(450 \mathrm{~km}$ from the rectifier side). According to the above analysis, the protection device should be judged as disturbance at this time, and the protection should reliably not operate.

It can be seen that for the four different situations of lightning 
TABLE II

LightNING Disturbance IDENTIFICATION Results

\begin{tabular}{lccccc}
\hline \hline Case & $\begin{array}{c}\text { Lightning } \\
\text { Waveform }\end{array}$ & $\begin{array}{c}\text { Lightning } \\
\text { Current }\end{array}$ & $\begin{array}{c}\text { Dis- } \\
\text { tance }\end{array}$ & $\rho_{\mathrm{U}}$ & Results \\
\hline Induced & $1.2 / 50 \mu \mathrm{s}$ & $5.9 \mathrm{kA} \mathrm{(+)}$ & & 0.3345 & $\mathrm{LD}$ \\
Lightning & $2.6 / 50 \mu \mathrm{s}$ & $5 \mathrm{kA}(-)$ & 0.3626 & $\mathrm{LD}$ \\
& $5 / 100 \mu \mathrm{s}$ & & 0.6896 & $\mathrm{LD}$ \\
Lightning & $1.2 / 50 \mu \mathrm{s}$ & & & 0.076 & $\mathrm{LD}$ \\
Striking on & $2.6 / 50 \mu \mathrm{s}$ & $-80 \mathrm{kA}$ & & 0.0747 & $\mathrm{LD}$ \\
the Tower & $5 / 100 \mu \mathrm{s}$ & & $450 \mathrm{~km}$ & 0.2252 & $\mathrm{LD}$ \\
Lightning & $1.2 / 50 \mu \mathrm{s}$ & & & 0.9708 & $\mathrm{LD}$ \\
Striking on & $2.6 / 50 \mu \mathrm{s}$ & $-50 \mathrm{kA}$ & & 2.071 & $\mathrm{LD}$ \\
the Lightning & $5 / 100 \mu \mathrm{s}$ & & & 0.3345 & $\mathrm{LD}$ \\
Conductor & $1.2 / 50 \mu \mathrm{s}$ & & & 0.3626 & $\mathrm{LD}$ \\
Lightning & $2.6 / 50 \mu \mathrm{s}$ & $-15 \mathrm{kA}$ & & 0.6896 & $\mathrm{LD}$ \\
Striking on \\
the Conductor & $5 / 100 \mu \mathrm{s}$ & & & & \\
\hline
\end{tabular}

$\mathrm{LD}=$ lightning disturbance

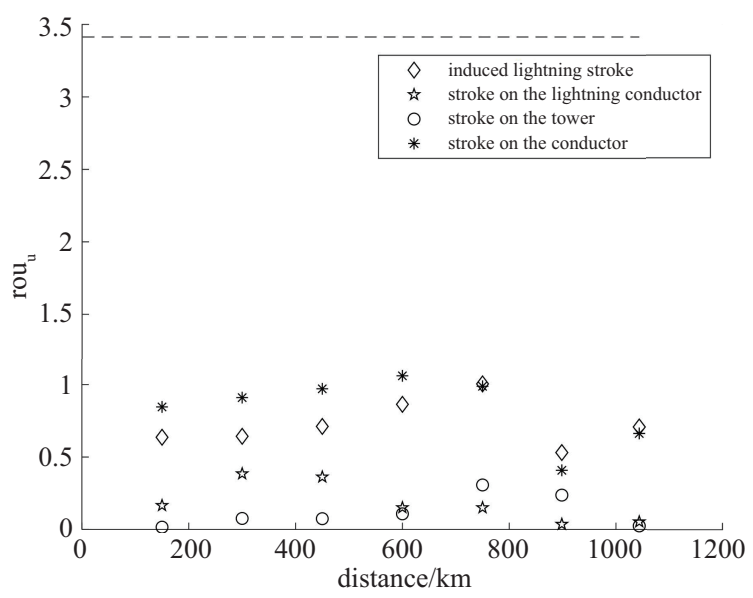

Fig. 8. Identification results of lightning disturbance at different distance.

disturbance, the ratio of the low-to-high-frequency energy of the 1 mode voltage component is less than the threshold, and the judgment results are all lightning disturbance, and the protection is reset. For lightning currents with different wave head and wave tail parameters, the results are not affected, indicating that the method has good adaptability.

When the distance between the lightning strike and the protection installation location changes, the result of this scheme is shown in Fig. 8.

In the figure, the dotted line is the threshold for identifying faults and disturbances. If the data point is above the dotted line, the protection operates; otherwise, the protection returns. It can be seen from the figure that when the lightning disturbance occurs at different positions, the low-to-high-frequency energy ratio of the 1 mode voltage component is small, and the threshold is more than 2 times higher than the value. This indicates lightning disturbances at different positions of the line can be distinguished significantly. Also, the result is not affected by the traveling wave refraction nor the distance, and appears good adaptability.
TABLE III

LightNing Fault IdENTIFICATION Results

\begin{tabular}{lcccccc}
\hline \hline Case & $\begin{array}{c}\text { Lightning } \\
\text { Waveform }\end{array}$ & $\begin{array}{c}\text { Light- } \\
\text { ning } \\
\text { Curr- } \\
\text { ent }\end{array}$ & $\begin{array}{c}\text { Dis- } \\
\text { tance }\end{array}$ & $\rho_{\mathrm{U}}$ & $\rho_{\mathrm{I}}$ & Results \\
\hline $\begin{array}{l}\text { Lightning } \\
\text { Striking }\end{array}$ & $1.2 / 50 \mu \mathrm{s}$ & & & 14.4431 & 3.3661 & $\mathrm{LF}$ \\
on the & $2.6 / 50 \mu \mathrm{s}$ & -120 & & 12.6655 & 0.9488 & $\mathrm{LF}$ \\
$\begin{array}{l}\text { Tower } \\
\text { Lightning }\end{array}$ & $5 / 100 \mu \mathrm{s}$ & $\mathrm{kA}$ & 450 & 17.7301 & 3.9929 & $\mathrm{LF}$ \\
$\begin{array}{l}\text { Striking } \\
\text { on the }\end{array}$ & $1.2 / 50 \mu \mathrm{s}$ & & $\mathrm{km}$ & 21.9339 & 3.9838 & $\mathrm{LF}$ \\
Conductor & $5 / 100 \mu \mathrm{s}$ & $\mathrm{kA}$ & & 19.5827 & 4.1468 & $\mathrm{LF}$ \\
\hline \hline
\end{tabular}

$\mathrm{LF}=$ lightning fault.

\section{B. Lightning Fault}

Table III investigates the situation where lightning currents with three different parameters occur at the same position of the line (450 km away from the rectifier side) causing flashover. According to the above analysis, the protection device should determine that a lightning fault has occurred, and proceed to the next judgment. The low-to-high-frequency ratio of the 1 mode voltage and current, and the discrimination results are shown in the following table.

It can be seen from Table III that the wave head and wave tail parameters of the lightning have little effect on the scheme. For lightning strikes in different situations, the energy ratio $\rho_{\mathrm{U}}$ is greater than the threshold, and it is judged that a fault has occurred. Then it needs to further determine whether the fault is caused by a lightning strike. Since the low-to-high-frequency energy ratio of the 1 mode current component in different situations is smaller, the judgment results are all lightning faults, and protection normally operates.

When the distance from the lightning strike point to the protection installation changes, the result of this scheme is shown in Fig. 9.

In Fig. 9(a), the dotted line is the threshold for identifying lightning disturbance and faults. If the data point is above the dotted line, the protection operates; otherwise, the protection returns. It can be seen that although the low-to-high-frequency energy ratio of the 1 mode voltage component is relatively scattered for the lightning faults occur at different locations, the calculated values are all over 1.5 times of the threshold. Therefore, the scheme can effectively distinguish between lightning disturbance and lightning faults. At the same time, it can be seen from Fig. 9(b) that the threshold between lightning and non-lightning faults is significantly greater than the energy ratio $\rho_{\mathrm{I}}$ when lightning faults occur. Therefore, the scheme can accurately determine whether the faults are caused by lightning strikes. When the location of the lightning strike points change, the scheme still has good adaptability.

\section{Non-lightning Faults}

Table IV investigates the occurrence of pole-to-ground and pole-to-pole short-circuit, including metallic short-circuits and short-circuits via different transition resistances at the same 


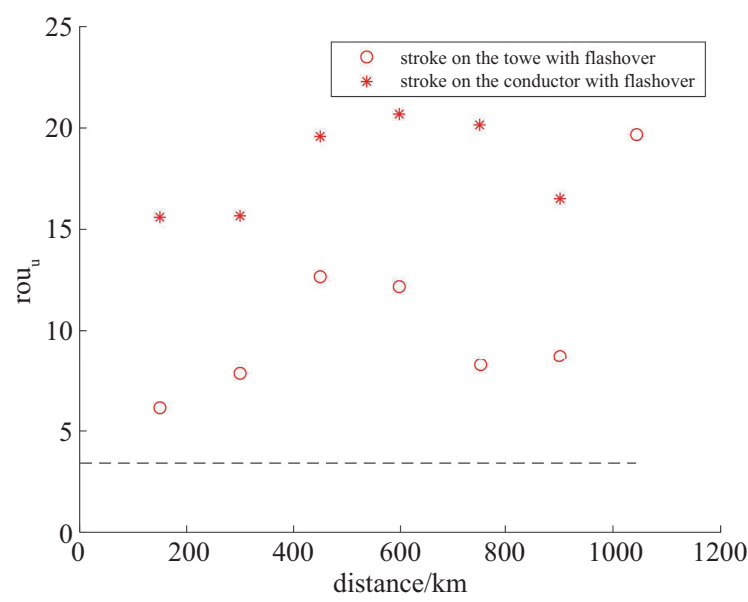

(a) Value of $\rho_{\mathrm{U}}$

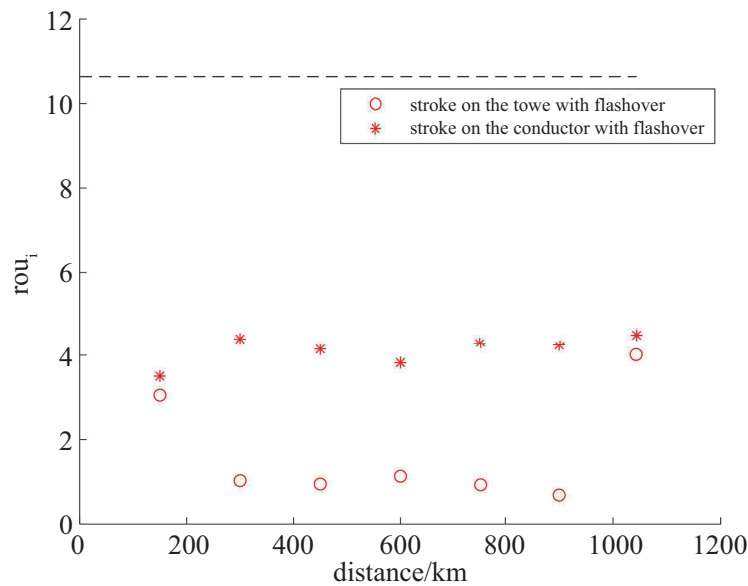

(b) Value of $\rho_{\mathrm{I}}$

Fig. 9. Identification results of lightning faults at different distance.

TABLE IV

Non-Lightning Fault Identification Results

\begin{tabular}{|c|c|c|c|c|c|}
\hline Case & $\begin{array}{l}\text { Transition } \\
\text { Resistance }\end{array}$ & Distance & $\rho_{\mathrm{U}}$ & $\rho_{\mathrm{I}}$ & Results \\
\hline \multirow{4}{*}{$\begin{array}{l}\text { Pole-to- } \\
\text { pole } \\
\text { short-cir- } \\
\text { cuit }\end{array}$} & 0 & \multirow{8}{*}{$450 \mathrm{~km}$} & 32.6804 & 23.5044 & $\mathrm{NF}$ \\
\hline & $100 \Omega$ & & 32.6886 & 21.3301 & $\mathrm{NF}$ \\
\hline & $200 \Omega$ & & 31.4546 & 40.9996 & $\mathrm{NF}$ \\
\hline & $500 \Omega$ & & 37.1095 & 39.666 & $\mathrm{NF}$ \\
\hline \multirow{4}{*}{$\begin{array}{l}\text { Pole-to- } \\
\text { ground } \\
\text { short-cir- } \\
\text { cuit }\end{array}$} & 0 & & 34.4283 & 31.9054 & $\mathrm{NF}$ \\
\hline & $100 \Omega$ & & 34.9645 & 29.59 & $\mathrm{NF}$ \\
\hline & $200 \Omega$ & & 25.1809 & 29.592 & $\mathrm{NF}$ \\
\hline & $500 \Omega$ & & 34.3977 & 36.8653 & $\mathrm{NF}$ \\
\hline
\end{tabular}

$\mathrm{NF}=$ non-lightning fault.

position of the line (450 $\mathrm{km}$ from the rectifier side). According to the above analysis, the protection device should determine that a non-lightning fault has occurred, and proceed to the next judgment. The low-to-high-frequency ratio of the 1 mode voltage and current, and the discrimination results are shown in the table.

It can be seen from the table that for non-lightning faults in

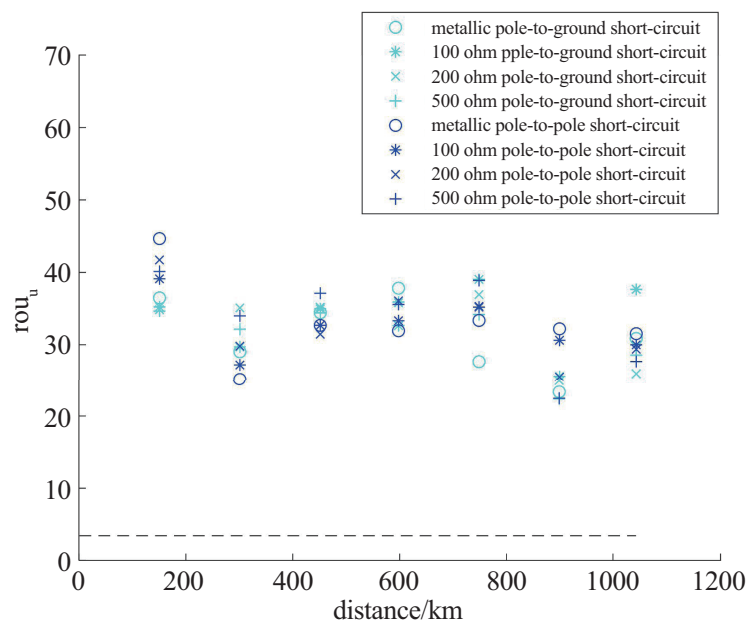

(a) Value of $\rho_{\mathrm{U}}$

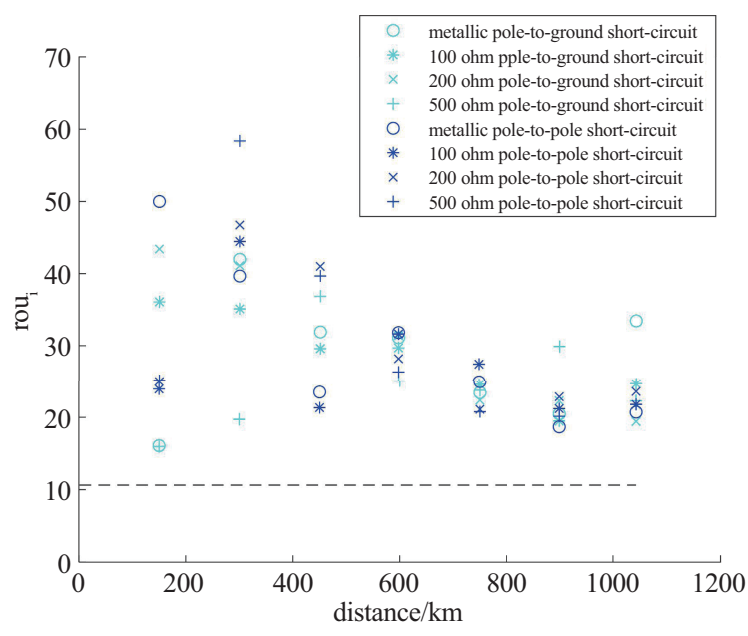

(b) Value of $\rho_{\mathrm{l}}$

Fig. 10. Identification results of non-lightning faults at different distance.

different situations, the low-to-high-frequency energy ratio of the 1 mode voltage component is greater than the threshold, and it is judged that a fault has occurred. At this time, it is necessary to further judge whether the fault is caused by lightning. Because the low-to-high-frequency energy ratio of the 1 mode current component in different situations is greater than the set threshold, the judgment result is that a non-lightning fault has occurred and the protection normally operates. In addition, this solution can also make accurate judgment even after a shortcircuit via $500 \Omega$ transition resistance, and has a strong ability to withstand the transition resistance.

When the distance between the fault point and the protection installation location changes, the results of this scheme are shown in Fig. 10.

In Fig. 10(a) the dashed line is the threshold for identifying faults and disturbance. The data point above the dotted line indicates that the protection normally operates; otherwise, the protection is reset. It can be seen from Fig. 10(a) that when a non-lightning fault occurs at any location, the threshold for distinguishing disturbance and fault will be much smaller than the low-to-high-frequency energy ratio of the 1 mode voltage component. Hence, the protection will act reliably. 


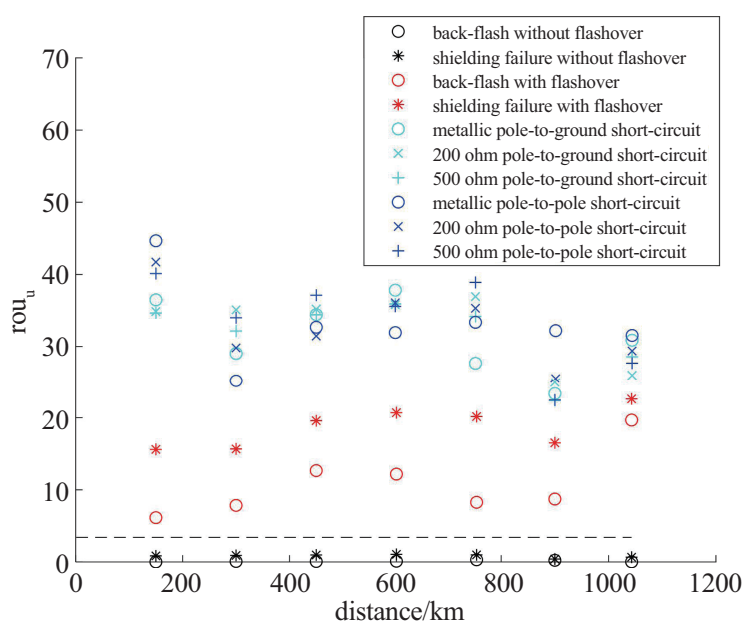

Fig. 11. Identification results of disturbance and faults at different distance.

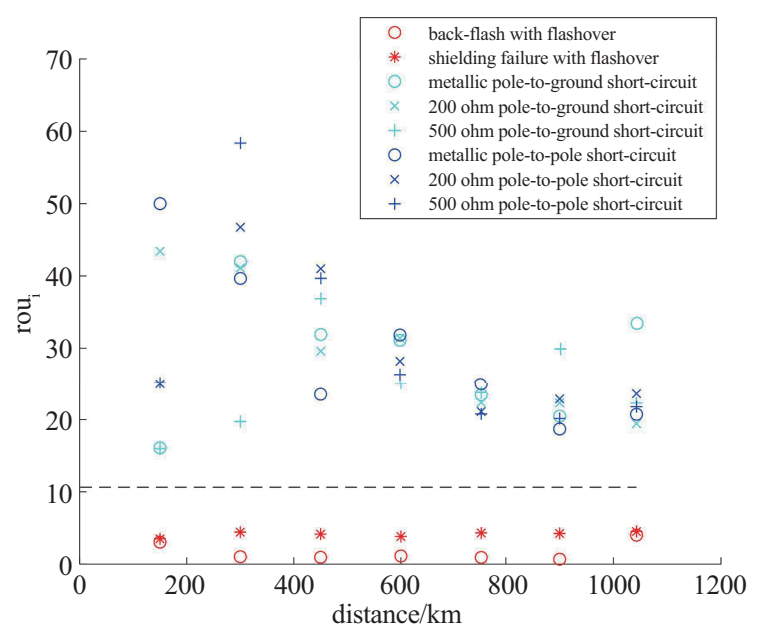

Fig. 12. Distinction results of lightning and non-lightning faults.

In Fig. 10(b) the dotted line is the threshold for identifying lightning and non-lightning faults. It can be seen from Fig. 10 (b) that although the low-to-high-frequency energy ratio of the 1 mode current component is quite different for nonlightning faults that occur at different locations, these values are still far higher than the threshold. This indicates that the scheme can accurately determine whether the fault is caused by lightning. In addition, it can be seen that transition resistance has little influence on the identification result.

\section{Summary}

Summarizing the simulation results above, we can obtain the identification results of the scheme when various disturbance or faults occur at different distances from the protection installation. The results can be used to identify interferences and faults, as shown in Fig. 11.

It can be seen that when lightning disturbance occurs at different locations, the distribution is concentrated and much smaller than the threshold. When lightning faults or common short-circuit faults occur, although the distribution is relatively scattered, the distance threshold still leaves a considerable margin. Therefore, the solution has good adaptability to disturbance or faults occurring in different locations, and is hardly affected by traveling wave refraction.

Fig. 12 shows the identification results of this scheme on lightning and non-lightning faults. It can be seen that the data points of lightning faults are concentrated below the threshold, while the data points of non-lightning faults are scattered above the threshold. Both of them leave a large margin with the threshold, so this scheme can effectively determine whether the fault is caused by lightning.

\section{CONCLUSION}

This paper mainly studies the following aspects:

- constructing a model of the HVDC transmission system including lightning strokes;

- extracting transient features of lightning disturbance, lightning fault and non-lightning fault in the time and frequency domain;

- proposing an identification scheme for the above three cases based on CEEMD-HHT;

- verifying the scheme through simulation tests.

Identification results show that the scheme overcomes the defects in the previous studies, such as being vulnerable to lightning current parameters and transition resistance, difficulty in setting thresholds, and long data window. With a $3 \mathrm{~ms}$ data window and a sampling rate of $1 \mathrm{MHz}$, the scheme can make a highly accurate judgment and appears good adaptability in different situations.

\section{REFERENCES}

[1] D. Divan and P. Kandula, "Distributed power electronics: an enabler for the future grid," in CPSS Transactions on Power Electronics and Applications, vol. 1, no.1, pp. 57-65, Dec. 2016.

[2] A. B. Nassif, "A protection and grounding strategy for integrating inverter-based distributed energy resources in an isolated microgrid," in CPSS Transactions on Power Electronics and Applications, vol. 5, no. 3, pp. 242-250, Sept. 2020.

[3] B. Li, J. Hu, S. Zhou, and D. Xu, "Hybrid back-to-back MMC system for variable speed AC machine drives," in CPSS Transactions on Power Electronics and Applications, vol. 5, no. 2, pp. 114-125, Jun. 2020.

[4] B. Wareing, "The effects of lightning on overhead lines," in Proceedings of IEE Seminar on Lightning Protection for Overhead Line Systems, London, UK, Dec. 2000, pp. 1-15.

[5] F. Kong, Z. Hao, S. Zhang, and B. Zhang, "Development of a novel protection device for bipolar HVDC transmission lines," in IEEE Transactions on Power Delivery, vol. 29, No. 5, pp. 2270-2278, Oct. 2014.

[6] M. Kong, X. Pei, H. Pang, J. Yang, and X. Zhou, "A lifting wavelet-based protection strategy against DC line faults for Zhangbei HVDC Grid in China," in Proceedings of 2017 19th European Conference on Power Electronics and Applications (EPE'17 ECCE Europe), Warsaw, Poland, Sept. 2017.

[7] H. Shu, B. Zhang, G. Zhang, and K. Liu, "Identification of lightning disturbance in UHVDC transmission lines using average voltage based on short window data," in High Voltage Engineering, vol. 36, no. 9, pp. 2180-2186, Sept. 2010.

[8] D. Yu, "Identification analysis of lightning stroke and fault location on the double-circuit HVDC transmission lines," M.S. thesis, School of Electric Power Engineering, Kunming University of Science and Technology, Kunming, China, 2016. 
[9] H. Shu, G. Zhang, S. Sun, Y. Wang, Z. Zhu, and S. Zhu, "Identification of shielding failure and back striking in UHVDC transmission lines," in Proceedings of the CSEE, vol. 29, no. 7, pp. 13-19, Mar. 2009.

[10] H. Shu, Y. Wang, C. Cheng, and S. Sun, "Analysis of electromagnetic transient and fault detection on $\pm 800 \mathrm{kV}$ UHVDC transmission lines under lightning stroke," in Proceedings of the CSEE, vol. 28, no. 19, pp. 93-100, Jul. 2008.

[11] K. Liu, H. Shu, J. Yu, X. Tian, and W. Wu, "Transient identification of lightning strokes on $\pm 800 \mathrm{kV}$ UHVDC transmission lines," in Power System Technology, vol. 37, no. 11, pp. 3007-3014, Nov. 2013.

[12] S. Chen, R. Cao, G. Bi, X. Li, and J. Rong, "Identification of UHVDC transmission line lightning disturbance based on morphology," in Electric Power, vol. 47, no. 10, pp.40-46, Oct. 2014.

[13] R. Cao, "The UHVDC transmission line transient protection and lightning disturbance identification research," M.S. thesis, School of Electric Power Engineering, Kunming University of Science and Technology, Kunming, China, 2015 .

[14] H. Wang, W. Wu, S. Zhang, Y. He, H. S.-H. Chung, and F. Blaabjerg, "A modified aalborg inverter extracting maximum power from one PV array source," in CPSS Transactions on Power Electronics and Applications, vol.4, no.2, pp. 109-118, Jun. 2019.

[15] W. Huang, Q. Cher, L. Han, and Y. Qi, "New recognition method of lightning interference in long distance VSC-HVDC transmission system," in Proceedings of 2018 China International Conference on Electricity Distribution (CICED), Tianjin, China, Sept. 2018, pp.1818-1823.

[16] Z. Xie, G. Zou, L. Gao, J. Zhang, and H. Gao, "Voltage pole-wave protection scheme for multi-terminal DC grid," in The Journal of Engineering, vol. 2019, no. 16, pp. 806-811, Nov. 2018.

[17] F. Kong and B. Zhang, "A novel disturbance identification method based on empirical mode decomposition for HVDC transmission line protection," in Proceedings of 12th IET International Conference on Developments in Power System Protection (DPSP 2014), Copenhagen, Denmark, Mar.-Apr. 2014, pp. 1-6.

[18] Z. Li, G. Zou, T. Du, and W. Yang, "S-transform based pilot protection method for HVDC transmission lines," in Proceedings of the CSEE, vol. 35, no. 6, pp. 1228-1235, May 2016.

[19] Z. Dai, N. Liu, C. Zhang, X. Pan, and J. Wang, "A pilot protection for HVDC transmission lines based on transient energy ratio of DC filter link," in IEEE Transactions on Power Delivery, vol. 35, no. 4, pp. 1695 1706, Oct. 2019.

[20] A. Christe, M. Petkovic, I. Polanco, M. Utvic, and D. Dujic, "Auxiliary submodule power supply for a medium voltage modular multilevel converter," in CPSS Transactions on Power Electronics and Applications, vol. 4, no. 3, pp. 204-218, Sept. 2019.

[21] J. Mei, R. Ge, Z. Liu, X. Zhan, G. Fan, P. Zhu, and W. Chen, “An auxiliary fault identification strategy of flexible HVDC based on convolutional neural network with branch structures," in IEEE Access, vol. 8, pp. 115922-115931, Jul. 2020.

[22] G. Luo, M. Cheng, H. Sun, M. Li, Y. Tan, J. He, and H. Zhang, "Stacked auto-encoder-based transients recognition in VSC-HVDC," in IEEE Access, vol. 8, pp. 14223-14233, Jan. 2020.

[23] G. Luo, C. Yao, Y. Tan, and Y. Liu, "Transient signal identification of HVDC transmission lines based on wavelet entropy and SVM," in The Journal of Engineering, vol. 2019, no. 16, pp. 2414-2419, Jan. 2019.

[24] X. Xiong, X. Wang, D. Liu, F. Blaabjerg, and C. Zhao, "Common-mode insertion indices compensation with capacitor voltages feedforward to suppress circulating current of MMCs," in CPSS Transactions on Power Electronics and Applications, vol. 5, no. 2, pp. 103-113, Jun. 2020.

[25] R. Cao, "Study of non-unit transient-based protection for HVDC transmission line," M.S. thesis, School of Electrical Engineering, Xi'an Jiaotong University, Xi'an, China, 2009.

[26] M. Szechtman, T. Wess, and C. V. Thio, "First benchmark model for HVDC control studied," in Electra, vol. 135, no. 4, pp. 54-73, Apr. 1991.

[27] C. F. Wagner and G. D. McCann, "Induced voltages on transmission lines," in Transactions of the American Institute of Electrical Engineers, vol. 61, no.12, pp. 916-930, Dec. 1942.

[28] S. Chen, X. Wang, B. Li, and S. Yang, "Frequency spectrum of standard lightning currents and its application," in Meteorological Monthly, vol. 32, no. 10, pp. 11-19, Oct. 2006.

[29] W. Shi, Y. Qiu, and Q. Zhang, in Fundamentals of High Voltage Engineering, Machinery Industry Press, Beijing, China, pp. 31, 2008.

[30] H. Ye, J. He, H. Li, and F. Lin, "Simulation of overvoltage and flashover caused by lightning stroke at towers of HVDC transmission line," in Power System Technology, vol. 29, no. 21, pp.31-35, Nov. 2005.

[31] J. Cai, "Protection of lightning and selection for insulation of equipment on 500 kV Shaheying Substation in Jinxi," in Jilin Electric Power, vol. 1, no. 2, pp. 9-13, Feb. 2002

[32] Y. Zhang, Y. Gao, B. Du, and W. Shi, "New tower model in calculation of lightning protection on transmission line," in Journal of Xi'an Jiaotong University, vol. 38, no. 4, pp. 265-372, Apr. 2004.

[33] G. Song, D. Zhou, Z. Jiao, J. Suonan, and B. Yun, “A novel fault location principle for HVDC transmission line," in Automation of Electric Power System, vol. 31, no. 24, pp. 57-61, Dec. 2007.

[34] N. Zhu, X. Zhang, M. Chen, S. Igarashi, T. Fujihira, and D. Xu, "Turn-on oscillation damping for hybrid IGBT modules," in CPSS Transactions on Power Electronics and Applications, vol. 1, no. 1, pp. 41-56, Dec. 2016.

[35] H. Shu, in Power Engineering Signal Processing Application, 1st Ed., Beijing: Science Press, Beijing, China, pp. 323-360, 2009

[36] P. Shang, P. Li, A. Yang, and X. Chen, "Seismic high-recvolution timefrequency analysis based on CEEMDAN," in Geophysical Prospecting for Petroleum, vol. 58, no. 4, pp. 547-554, Jul. 2019

[37] Y. Si, R. Guo, and P. Shi, "Comparative study of signal time-frequency analysis techniques based on EMD, EEMD and CEEMD," in CT Theory and Applications, vol. 28, no. 4, pp. 417-426, Aug. 2019.

[38] S. Ren, H. Xiao, and Y. Li, "Practical setting principle of traveling wave protection for HVDC power transmission line," in Electric Power Automation Equipment, vol. 39, no. 9, pp. 54 -60, Sept. 2019

[39] X. Meng, "Research on HVDC line protection based on characteristic band analysis," M.S. thesis, School of Electrical and Power Engineering, China University of Mining and Technology, Xuzhou, China, 2020.

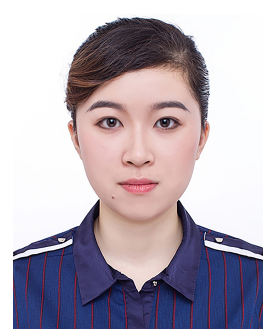

Dongmeng Ye received her B.S. degree in Schoo of Electrical Engineering, Southeast University, China, in 2020. She is currently a master student at Xi'an Jiaotong University. Her main field of interest includes the relay protection for HVDC.

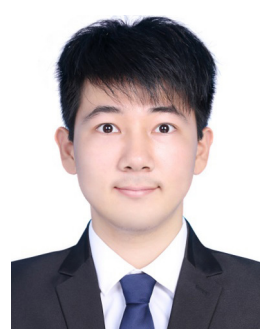

Fan Xie received the B.S. degree in electrica engineering from Xi'an Jiaotong University, China, in 2018. He is currently pursuing the Ph.D. degree with the School of Electrical Engineering in Xi'an Jiaotong University. His main field of interest includes the relay protection for HVDC.

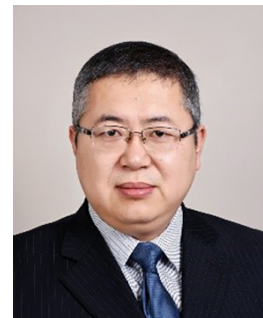

Zhiguo Hao was born in Erdos, China, in 1976. He received the B.Sc. and $\mathrm{Ph} . \mathrm{D}$. degrees in electrical engineering from Xi'an Jiaotong University, Xi'an, China, in 1998 and 2007, respectively. He is a Professor with the School of Electrical Engineering, Xi'an Jiaotong University, since 2020. His research interest is power system protection. 